\title{
Transüretral Rezeksiyon- Prostat (TUR-P) Ameliyatlarında ERAS Protokolü ile Ameliyat Öncesi ve Sonrası Yapılması Ge- reken Beslenme, Ağrı ve Erken Mobilizasyon Uygulamalarının Karşılaştırılması
}

\section{An Investigation of Preoperative and Postoperative Nutrition, Pain and Early Mobilisation Practices in TUR-P Surgery in Relation to the ERAS Protocol}

\author{
Rabia KANKILIÇ ${ }^{1}$, Arzu TUNA ${ }^{2}$ \\ ${ }^{1}$ Yüksek Lisans Öğrencisi, SANKO Üniversitesi Sağlık Bilimleri Enstitüsü Hemşirelik Anabilim Dalı, Cerrahi Hastalıkları Hemşireliği, \\ GAZİANTEP \\ ${ }^{2}$ Prof. Dr. SANKO Üniversitesi Sağlık Bilimleri Fakültesi, Hemşirelik Anabilim Dalı, Cerrahi Hastalıkları Hemşireliği, GAZİANTEP
}

\section{Öz}

Amaç: Yapılan bu çalışmada TUR-P ameliyatları sonrası Avrupảnın 5 ülkesinin bir araya gelerek oluşturdukları ameliyat sonrası hızlı iyileşme (ASHI) protokolünü Gaziantep’teki hastanelerde bulunan sağllk personelinin duyup duymadığını; ağrı, erken mobilizasyon ve beslenme konularının bakım ve tedavilerinde bu protokolün gerekliliklerini uygulayıp uygulamadığını tespit etmek istedik.

Gereç ve Yöntem: Gaziantep’te bulunan beş hastanesinin üroloji klinik hemşireleri, üroloji uzmanları ve anestezi uzmanlarına yönelik demografik özellikler bulunduran soru formlarıyla, üroloji servisinde TUR-P ameliyatı olan hastaların ASHİ protokolü ile ameliyat öncesi ve sonrası yapılması gereken beslenme, ağrı ve erken mobilizasyon uygulamalarının karşılaştırılması hakkındaki bilgiler belirlendi. Cerrahlara, hemşirelere ve anestezi uzmanlarına bu konuları içeren anket soruları uygulandı ve çalışmanın örneklemini 95 kişi oluşturdu. Araştırmacılar tarafından hazırlanan ankette 25 soru bulunmaktaydı. Araștırma öncesi etik kuruldan, tüm hastane ve katılımcılardan gerekli yasal izin alındı. Bu veriler 1 Nisan 2018 -10 Haziran 2018 tarihleri arasında yüz yüze görüşülerek toplandı. Cerrahların, hemşirelerin ve anestezi uzmanlarının ASHİ protokolüne göre bakım ve tedavilerindeki tutumları analiz edildi; değerlendirmede sayı yüzde kullanıldı.

Bulgular: Sağlık personelinin yaş ortalaması $34.73+9.11$ idi, sağllk personelinin $\% 26,3^{\prime}$ ü cerrah, $\% 17,9^{\prime}$ u anestezi uzmanı ve $\% 55,8^{\prime} \mathrm{i}$ hemşireydi. Hastalara ameliyatları öncesi, oral olarak karbonhidrattan zengin sıvı verme durumu \% 29,5 idi. "Ameliyat öncesi açlık süresi ASHİ Protokolüne uygundur" diyenlerin oranı \% 4,2 idi. Ameliyat sonrası sıvı ve katı gıda alım da ASHİ Protokolüne uygun değildi. Hastaların bulantı ve kusmasını önlemek amaciyla profilaksi uygulanma durumu \% 65,3'dü. “TUR-P ameliyatı sonrası antiembolik çorap uyguluyoruz" diyenlerin oranı \% 62.1 idi. Hastaları mobilize etme durumunda da ASHİ protokolüne uygun hareket edilmiyordu. "Ameliyat sonrası ağrı için analjezik yapılmalı" diyenlerin oranı \% 62,1 iken antienflamatuar ilaç seçimi oranı ise \% 44,2 idi. ASHİ protokolünü duyanların oranı \% 7,4'dü. ASHİ Protokolünü uygulayanların oranı ise \%37,9'du.

Sonuç: Yapılan bu çalışma sonucu ASHİ Protokolüne uygun bir bakım ve tedavi prosedürünün TUR-P ameliyatlarından sonra uygulanmadığı söylenebilir. Kanıta dayalı ASHİ protokolüne göre hemşirelik bakım paketlerinin ve tedavi prosedürlerinin üroloji kliniklerinde uygulanmaya başlatılması için hizmet içi eğitimlerin planlanması, tüm personelin ASHİ protokolüne benzeyen prosedürler oluşturması ve araştırmalar yapması için komitelerin kurulması sağlanmalıdır.

Anahtar Kelimeler: Ameliyat sonrası hızlı iyileșme protokolü, transüretral rezeksiyon prostat ameliyatı, hemşirelik

İletişim: Prof. Dr. Arzu Tuna, SANKO Üniversitesi Sağlık Bilimleri Fakültesi, Hemşirelik Anabilim Dalı, Cerrahi Hastalıkları Hemşireliği, Gaziantep

DOI:

$10.17517 /$ ksutfd.484635

\section{Abstract}

Objective: The objective of this study is to find out whether hospitals in Gaziantep, Turkey meet the requirements of the ERAS protocol regarding the implementation of postoperative nutrition, pain and early mobilisation practices in TUR-P surgeries.

Materials and Methods: This study was carried out in the urology clinics of five hospitals. The attitudes of the surgeons, nurses and anaesthetists $(n=95)$ were analysed in accordance with the ERAS protocol. The surgeons, nurses and anaesthetists were asked survey questions about pain, early mobilisation and nutrition. The sample group consisted of ninety-five persons. The questionnaires were conducted by using a face-to-face method. The results of the questionnaires were given in percentages.

Results: The average age of the health personnel is $34.73+9.11$. Them of $26.3 \%$ was surgeon, while $17.9 \%$ of them was anaesthetist and $55.8 \%$ of them was nurse. The preoperative fluid intake richer than carbohydrate was $29.5 \%$. The rate of those stating that the duration of patency was in accordance with the ERAS protocol is \%4.2. The process of postoperative fluid and intake was not in line with the requirements of the ERAS protocol. The rate of those suggesting that prophylaxis must be implemented for nausea was $65.3 \%$. The rate of those stating that they used anti-embolic stockings after each TUR-P surgery was $62.1 \%$. The rate of the mobilisation of the patients after TUR-P surgery did not either meets the requirements. The rate of those stating that analgesic must be used for postoperative pain was $62.1 \%$, while anti-inflammatory drugs were preferred after operations and its rate was $44.2 \%$. The rate of those who heard about the ERAS protocol was $37.9 \%$.

Conclusion: Considering the findings of this study, it can be pointed out that the treatment and care procedures were not conducted in accordance with the requirements of the ERAS protocol. In order to start treatment procedures and nursing care plans in accordance with the ERAS protocol, it can be suggested that health personnel should have in-service trainings and that similar procedures to those of the ERAS protocol can be organised and put into action by means of different committees.

Key Words: Enhanced recovery after surgery, Transurethral Resection - Prostate Surgery, nursing

$\begin{array}{lll}\text { Tel } & : & 05317920104 \\ \text { E-Posta } & : & \text { arzutunam@gmail.com olacak } \\ \text { Geliş Tarihi } & : & 18.11 .2018 \\ \text { Kabul Tarihi } & \text { : } & 16.03 .2019\end{array}$




\section{GİRIŞ}

Kanıta dayalı uygulamalar ile hastaların tedavi ve bakım standartları yaklaşık 30 yıldır hasta güvenliğini sağlamak adına önem kazanmıştır (1). Tedavi ve bakımlar standartlaşmış kanıta dayalı protokollerle tek çatı altında toplanmıştır. Güncel araştırmalar ve deneysel çalışmalar ile hastaların sağlığ 1 , konforu, hastaneden erken taburculuğu genel iyilik hali, var olan sağlık problemi dışında gelişebilecek durumları önlemek amacıyla yapılmış çalışmalar bulunmaktadır. Bulunan zaman diliminde mortalite ve morbidite oranları azalsa da gelişen teknoloji ile daha iyiye gitme umudu artmaktadır (2).

Ameliyat sonrası dönemde ağrı, bulantı-kusma, bağırsak tıkanıklığı veya yapışıklığı, nefes alıp vermekte bozulma ve kalp yükünün artması gibi şikayetler görülebilmektedir. $\mathrm{Bu}$ problemlerde erken hareket etmeyi (mobilizasyonu) ve ağızdan beslenmeyi geciktirmek, taburculuk süresini uzatarak hastanede kalış süresini arttırmaktadır. Bu ve benzeri komplikasyonlarla hastanın mortalite ve morbidite riski artmaktadır (3). Hastalarda görülen bu komplikasyonların oluşmaması adına geleneksel bakım ve tedavilere karşı kanıta dayalı yeni çalışmalara ihtiyaç duyulmuştur. 1990'lı yılların başında ASHİ (Ameliyat Sürecinde Hızlı İyileştirme- ERASEnhanced Recovery After Surgery) protokolü oluşturulmuştur (4-10).

ASHİ protokolüne göre ameliyat sırasında tercih edilen anestezik ilaçların özelliği; ameliyattan sonra hastanın en hızlı dönemde iyileşmesini ve analjeziye olan ihtiyacın en alt seviyede olmasını sağlamalı, normal yaşamsal faaliyetlerini yerine getirmeyi sağlayacak özellikte olmalıdır (5).

ASHİ protokolüne göre hastaların ameliyat sonrası en erken dönemde yataktan kalkmaları ve yürümeleri solunum fonksiyonlarını olumlu etkiler, akciğerlerinde atalektaziyi önler, bağırsak hareketlerini, peristaltizmi arttırır ve hareketsizlikle oluşabilecek insülin direncindeki bozulmayı önler. Ek olarak yara yeri iyileşmesini de olumlu etkiler (6). Erken mobilizasyona ek olarak, erken ağızdan beslenme ve dengeli analjezi ameliyattan sonra iyileşmeyi hızlandırır (7).

ASHİye olan ihtiyaç ameliyat öncesi; hastanın korku ve endişesini gidermek, ameliyat sırasında; hipotermiyi önlemek, insizyon kesisini küçültmek, gereksiz diren kullanımını engellenmek, ameliyat sonrası en erken dönemde beslenmek ve en kısa zamanda mobilizasyonu sağlanmak gibi 21 maddelik konu başlıklarını ortaya çıkarmıştır (8). ASHI protokolü multidisipliner yaklaşım gerektirmektedir. Bunun için cerrahlar, anestezistler, hemşireler, fizyoterapistler ve diyetisyenlerle hazırlanmış ASHİ protokolüne uygun çalışmak gerekmektedir (9).

Geleneksel tedavi yönteminde ameliyat öncesi hastaya gece 12 den sonra aç kalması önerilmektedir. Böylelikle hastanın 8 saati aşkın süre aç, susuz kalması dehidratasyona sebep olmakta, uzun süre aç kalması sebebiyle hastanın insülin direnci artmakta ve hücresel açlık metabolik asidoza neden olmaktadır. Bunu engellemek amacıyla ASHİ protokolü ile kanıta dayalı beslenme programı hazırlanmıştır (10).

Ameliyat sırasında gelişen hipotermi sağlık problemlerine yol açmaktadır. ASHİ protokolüne göre ameliyat sırasında hastanın vücut ısısını korumak gerekmektedir. Vücut sıcaklığını korumak ve tüm sistemlerin olumsuz etkilenmesini önlemek için batın ve perine ameliyatlarında ASHİ protokolü mümkünse epidural anesteziyi önermektedir. Epidural anestezi, ameliyat sonrası analjeziye olan ihtiyacı azalttı̆̆ için uygun görülmektedir (7). Üroloji ameliyatlarında TUR-P (Transüretral Rezeksiyon-Prostat) vakalarında da ASHİ protokolü ile daha sağlıklı birey sonuçları alınmaktadır (10).

ASHİ protokolü ile birçok cerrahi alanda çalışmalar yapılmıştır. Bunlara örnek olarak kolon cerrahisi, kalça, diz ve omuz rekonstrüksiyon, vajinal histerektomi, gastrikfundoplikasyon, splenektomi, adrenalektomi, donör nefrektomi, mastektomi, kolesistektomi, total kalça ve diz replasmanı, aort anevrizmektomi, pnömonektomi, radikal prostatektomi, periferikvasküler rekonstrüksiyon gösterilebilir. Ürolojide kanıta dayalı ASHİ protokolü uygulanmaya başlanmıştır (4-10).

TUR-P ameliyatı olan hastaların ağrı, beslenme ve erken mobilizasyon konularının ASHİ protokolü ile ameliyat öncesi ve sonrası hastalara verilen bakım, tedavinin Gaziantep ilinde nasıl uygulandığını belirlemek amacıyla bu araştırma yapıldı.

\section{GEREÇ VE YÖNTEMLER}

$\mathrm{Bu}$ araştırmada; Türkiye’nin güneydoğusunda yer alan Gaziantep ilindeki 25 Aralık Devlet Hastanesi, Dr. Ersin Arslan Eğitim ve Araştırma Hastanesi, Gaziantep Üniversitesi Şahinbey Araştırma ve Uygulama Hastanesi, Özel SANKO Eğitim, Uygulama ve Araştırma Hastanelerinin üroloji servisinde çalışıldı. Araştırma verileri bir devlet hastanesi, bir özel hastane, bir eğitim araştırma hastanesi ve bir üniversite hastanesini kapsaması amaciyla bu hastaneler tercih edildi. Araştırmanın verileri 1 Nisan 2018 -10 Haziran 2018 tarihleri arasında toplandı. Yapılan bu araştırma tanımlayıcı tipteydi. Araştırmanın evrenini üroloji kliniğinde bulunan cerrahların, anestezi uzmanlarının ve hemşirelerinin tümü oluşturdu. Tüm üroloji kliniğinde bulunan cerrahların, anestezi uzmanların ve hemşirelerin sayısı 117 kişi idi. Araştırma anketine 95 kişi katıldı, ankete yanıt veren çalışanlar da örneklemi oluşturdu.

\section{Veri Toplama Araçları:}

Yaş, cinsiyet, kurumda çalıştı̆̆ 1 deneyim yılı, pozisyonu yanı sıra “ TUR-P ameliyatlarında ASHİ protokolü ile ameliyat öncesi ve sonrası yapılması gereken beslenme, ağrı ve erken mobilizasyon uygulamalarının karşılaştırılması" adına anket soruları veri olarak toplandı. Araştırmacılar tarafından hazırlanan ankette 25 soru bulunmaktaydı. Soru formu; yaş, cinsiyet, eğitim durumu, meslek, çalışılan yıl süresi, ameliyat öncesi danışmanlığı kimin verdiği, bilgi verme yöntemi, hazırlanmış bakım ve tedavi prosedürünün var olup olmadığı, hasta başına düşen hemşire sayısı, ameliyattan önce karbonhidratlı sıvı verilip verilmediği, ameliyat öncesi açlık süresi, ameliyat sonrası sıvı alım süresi, ameliyat sonrası katı alım süresi, ameliyat sonrası profilaksi bulantı kusma uygulanıp uygulanmadığı, ameliyat sonrası DVT çorabı uygulayıp uygulamadıkları, ameliyat sonrası; mobilizasyon, ağrı için analjezik kullanımı, ne tür ilaç grubunun kullanıldığı, spinal anestezinin kan şekerini olumsuz etkileyip etkilemediği, hastalar taburcu olurken üriner kateterinin çıkarılıp çıkarılmadığı ve ASHI protokolünü duyup duymadıkları, uygulayıp uygulamadıkları soruldu. Veriler sayı yüzde olarak analiz edildi. Çalışma öncesinde SANKO Üniversitesi Klinik Araştırmalar Etik Kurulu'ndan (tarih: 30.03.2017-3 Karar no=1) ve Gaziantep Üniversitesi Şahinbey Araştırma ve Uygulama Hastanesi, Dr. Ersin Arslan Eğitim ve Araştırma 
Hastanesi, 25 Aralık Devlet Hastanesi, Özel SANKO Eğitim, Uygulama ve Araştırma Hastanelerinin üroloji klinik sorumlu hekimlerinden izin alındı. Araştırmacı tarafından geliştirilen soru formu üroloji servislerinde hizmet veren cerrahlara, anestezi uzmanlarına ve hemşirelere uygulandı. Araştırmacı tarafından yapılan veriler yüz yüze toplandı.

\section{BULGULAR}

Araştırmaya katılan sağlık çalışanlarının sosyodemografik verileri Tablol 'de verildi. Katılımcıların yaş ortalamaları 34.73+ 9.11 (min:20, max: 56) idi. Çalıșanların \% 38.9'u ( $\mathrm{n}=37)$ kadındı. Araştırmaya katılan meslek gruplarına baktığımızda \% 55.8'i (n=53) hemşire, \% 26.3'ü $(n=25)$ cerrah, $\% 17.9$ 'u $(\mathrm{n}=17)$ anestezistlerden oluşmaktaydı.

Tablo 1. Araştırmaya katılan sağlık çalışanlarının (hemşire, anestezist, cerrah) sosyo-demografik özellikleri $(n=95)$

\begin{tabular}{|l|l|l|}
\hline $\begin{array}{l}\text { Sosyo-demografik } \\
\text { Özellikleri }\end{array}$ & Sayı n & Yüzde \% \\
\hline Yaş & $\begin{array}{l}\text { 34.73+9.11 (min:20, } \\
\text { max: 56) }\end{array}$ & \\
\hline Cinsiyet & \multicolumn{3}{|l|}{} \\
\hline Kadın & \multicolumn{2}{|l|}{} \\
\hline Erkek & 58 & 38.9 \\
\hline Eğitim Durumu & 61.1 \\
\hline Sağlık Meslek Lisesi & 6 & 6.3 \\
\hline Ön lisans & 18 & 18.9 \\
\hline Lisans & 28 & 29.5 \\
\hline Lisansüstü & 43 & 45.3 \\
\hline Mesleki Pozisyonu & \multicolumn{2}{|l|}{} \\
\hline Hemşire & 53 & 55.8 \\
\hline Cerrah & 25 & 26.3 \\
\hline Anestezist & 17 & 17.9 \\
\hline Kaç yıldır bu pozisyonda çalışmaktasını? & \\
\hline $0-5$ yıl & 54 & 56.8 \\
\hline $6-10$ yll & 34 & 35.8 \\
\hline $11-15$ yll & 3 & 3.2 \\
\hline $16-20$ & 2 & 2.1 \\
\hline $249-510$ & 2 & 2.1 \\
\hline
\end{tabular}

Ankete katılan sağlık personellerinin yaptıkları meslekte çalışma yıllarına baktığımızda 0-5 yıl arası \% $56.8(\mathrm{n}=54), 6-10$ yıl \% $35.8(\mathrm{n}=34), 11-15$ yıl \% $3.2(\mathrm{n}=3), 16-20$ yıl üzeri \% 2.1 $(n=2), 249-510$ yıl üzeri \% $2.1(n=2)$ olduğu görüldü (Tablo 1$)$.

Sağlık personellerine TUR-P ameliyatları hakkında ameliyat öncesi danışmanlık eğitimini hangi meslek grubundan veriliyor diye sorduğumuzda; \% 22,1 ( $\mathrm{n}=21)$ cerrah, \% 77,9 $(n=74)$ hepsi (anestezist, cerrah, hemşire) vermekteydi.

TUR-P ameliyatı olacak hastalara yapılacak olan eğitimlerin, \% 98,9’u (n=94) yüz yüze görüşme ile \% 1,1’i (n=1) yüz yüze görüşme ve broşür ile verildiği iletildi.

“TUR-P ameliyatlarında tedavi ve bakımın yürütülmesi için hazırlanmış tedavi ve bakım paketleri veya prosedürleri var mı?” diye sağlık personellerine sorulduğunda \% 71,6 $(\mathrm{n}=68)$ evet, \% 28,4 $(\mathrm{n}=27)$ hayır dedi. Ancak hemşirelik bakım paketlerinin olmadığı tedavi için de doktorların kendilerine ait prosedürlerin olduğu bunların da yazılı metin olmadığı ortaya çıtı.

Üroloji servisinde spinal anestezi ile TUR-P ameliyatı olan her bir hastaya kaç hemşire düşmektedir diye sağlık personeline sorduğumuzda \% 29,5 $(\mathrm{n}=28) 1$ hastaya 1 hemşire, $\%$ 30,5 $(\mathrm{n}=29) 2$ hastaya 1 hemşire, \% 34,7 $(\mathrm{n}=33) 3$ hastaya 1 hemşire, \% 5,3 $(\mathrm{n}=5) 4$ ve daha fazla hastaya 1 hemşire bakım verdiği iletildi (Tablo 2).

Spinal anestezi ile TUR-P ameliyatlarında hem katı hem de sıvı alımının kesilmesi, hastanın aç kalması demekti. Hastalar ameliyat önceki, gece yarısından sonra aç bırakılıyordu ve bu ifadeyi kullanan sağlık personeli \% 57,9 (n=55)'du. Spinal anestezi alacak hastaların ameliyattan sekiz saat önce katı ve sıvı gıdalarının kesilmesini ifade eden sağlık personeli de \% 37,9 'du $(n=36)$.

Hastaların TUR-P ameliyat öncesi oral sıvı olarak karbonhidrattan zengin besin verilmeli diye ifade edenler \% $29,5(n=28)$, edemeyenler \% 70,5 ( $n=67)$ 'di. Hastalara ameliyat sonrası sıvı desteğin tüm sağlık çalışanları vermekteydi, sadece ameliyat öncesi diyabet hastalarının kan şekeri takibi rutinde yapılmakta, hastaların açlık düzeylerinin kan şekerine, kan gazlarına (asidoz olarak) etkisi \%100 sağlık personeli tarafından izlenmemekteydi.

TUR-P ameliyatı olmuş hastalara ameliyatlar sonrası dönemde ne zaman oral sıvı almaya başlıyor diye sorduğumuzda sağlık personelinin \% 62,1'i $(n=59)$ ameliyat günü, \% 10,5’i $(\mathrm{n}=10)$ doktor isteyince, \% 27,3’ü $(\mathrm{n}=26)$ dedi.

Spinal anestezi ile TUR-P ameliyatı olmuş hastalarınıza ameliyat sonrası ne zaman katı gida veriyorsunuz diye sorduğumuzda; katılımcıların \% 3,2'si ( $\mathrm{n}=3)$ ameliyattan 4 saat sonra, \% 26,5 $(\mathrm{n}=25)$ ameliyattan 8 saat sonra, \% $70.5(\mathrm{n}=67)$ gaz çıkışı olunca diye ifade etti.

TUR-P ameliyatı geçiren tüm hastalarınıza ameliyat sonrası bulantı ve kusma profilaksi uygulama durumu sorulduğunda katılımcıların \% 65,3'ü $(\mathrm{n}=62)$ evet, \% 34,7'si $(n=33)$ hayır diye belirtti.

“TUR-P ameliyatı sonrasında hastalarınızın en erken dönemde mobilizasyonu önemlidir. Hastalarınızı ayağa kaldırıp yürüttüğünüz saat dilimi nedir ” diye sorduğumuzda sağllk personellerinin, \%74,4'ü ( $\mathrm{n}=71)$ ilk $52-56$ saat sonra,\% 20,0'si $(n=19)$ ilk 8-24 saatten sonra, \% 5,3'ü $(n=5)$ hastayı yürüttüklerini ifade etti.

TUR-P ameliyatını spinal aneztezi ile olan tüm hastalara antiembolik tedavi uygulanıyor mu diye sorduğumuzda katılımciların \% 37.9'si $(n=36)$ evet, \% 62.1'i $(n=59)$ hayır diye ifade etti.

Sağlık personellerine TUR-P ameliyatı geçiren hastaya ağrı kesici ilaç uygulamasında tercihleri sorulduğunda ; \% $44,2(n=42)$ antienflamatuarlar, \% 33,7 $(n=32)$ parasetemoller, $\% 4,2(\mathrm{n}=4)$ epidural opioidler, \% $17.9(\mathrm{n}=17)$ intramuskuler opioidleri kullandıklarını belirttiler.

Sağlık personellerine TUR-P ameliyatı olmuş tüm hastalarda taburcu olurken üriner kateterini çıkarıyor musunuz? diye sorduğumuzda; \% 63.1'i $(n=60)$ evet, \% 36.8'i $(\mathrm{n}=35)$ hayır olarak cevap verdi.

Üroloji kiniğindeki cerraha, anestezi uzmanına ve 
Tablo 2. TUR-P ameliyatlarında görev alan doktor ve hemşirelere yönelik bilgilerin incelenmesi

\begin{tabular}{|c|c|c|}
\hline Sorular $(n=95)$ & Say1 & $\%$ \\
\hline \multicolumn{3}{|c|}{ TUR-P ameliyatı öncesi hasta bilgilendirmesi kim|kimler tarafından verilmektedir? } \\
\hline Cerrah & 21 & 22.1 \\
\hline Hepsi (Anestezist, Hemşire, Cerrah) & 74 & 77.9 \\
\hline \multicolumn{3}{|c|}{ Hastalarınızı ameliyattan önce nasıl bilgi verirsiniz? } \\
\hline Yüz yüze bilgi verme & 94 & 98.9 \\
\hline Yüz yüze ve broșür & 1 & 1.1 \\
\hline \multicolumn{3}{|c|}{$\begin{array}{l}\text { Servisinizdeki doktorların/hemşirelerin TUR-P ameliyatlarında bakımı yürütmesi için hazırlanmış tedavi ve bakım } \\
\text { paketleri, prosedürler var mı? }\end{array}$} \\
\hline Evet & 68 & 71.6 \\
\hline Hayır & 27 & 28.4 \\
\hline \multicolumn{3}{|c|}{ Spinal anestezi ile TUR-P ameliyatı olan her bir hastaya kaç hemşire düşmektedir? } \\
\hline 1 hastaya 1 hemşire & 28 & 29.5 \\
\hline 2 hastaya 1 hemşire & 29 & 30.5 \\
\hline 3 hastaya 1 hemşire & 33 & 34.7 \\
\hline 4 ve daha fazla hastaya 1 hemşire & 5 & 5.3 \\
\hline
\end{tabular}

hemşireye ASHİ (Ameliyat Sonrası Hızlandırılmış İyileşme) Protokolünü (ERAS- FAST TRACT) duydunuz mu? diye sorduğumuzda \% 27.3'ü $(n=26)$ evet, \%72.6’sı $(n=69)$ hayır dedi.

Üroloji servislerinde ASHİ (ERAS (Enhanced Recovery After Surgery)/(Fast Tract Surgery) protokolünü TUR-P ameliyatları sonrası uygulamayıp uygulamadıklarını sorduğumuzda; sağlık personellerinin \% 5.2'si $(n=5)$ evet \% $94.7(\mathrm{n}=90)$ hayır ifadesinde bulundu (Tablo 3$)$.

\section{TARTIŞMA}

TUR-P Ameliyatlarında ASHI Protokolü ile Ameliyat Öncesi ve Sonrası Yapılması Gereken Beslenme Uygulamalarının Karşılaştırılması:

Geleneksel uygulamalarda genel anestezi alan hastaların ameliyat esnasında pulmoner olarak aspirasyon olabileceğinden ameliyattan 8-12 saat öncesinde oral olarak gıda alımı sonlandırılmaktaydı. Hastalar zamanında ameliyata alınmadığ 1 takdirde; hastaların ameliyat öncesi aç kalma dönemleri de uzun olmaktadır. Bu durum, açlık süresinin uzamasına neden olarak, insülin direncini arttırmakta, asidoz oluşturabilmekte, metabolizmayı olumsuz etkilemektedir. ASHİ protokolünde; bu nedenle hastaların anesteziden 6 saat önce katı gıda alımın kesilmesinin, 2 saat öncede berrak sıvı alımının kesilmesinin ameliyatı kolaylaştırabileceğine yönelik kanıta dayalı açıklamalar yer almaktadır (2). Buna ek olarak literatürde, hastaların enerji desteğinin sağlanması peristaltizmin devamlılı̆̆ için ameliyat önceki gece $800 \mathrm{cc}$, ameliyat sabahı da $400 \mathrm{cc}$ glikoz sıvı desteğinin oral olarak verilebileceği ASHİ protokolünde yer almaktadır (2).

Yuill ve ark. yaptıkları randomize kontrollü çalışmada ameliyat öncesi açlık süresini ASHI protokolüne göre tasarlayarak ulaştıkları sonuç vaka grubunda kas kütle kaybında azalma ve taburculuk süresinde hızlanma tespit edilmiştir. Bu ve benzeri çalışmalar sonucu karbonhidratlı içeceklerin güvenli olduğu kanitlanmıştır (11).

Araştırmamızda sağlık çalışanlarının (hemşire, anestezist, cerrah) hastaları TUR-P ameliyatı öncesi \% 57.9 $(\mathrm{n}=55)$ hastaları gece yarısından sonra aç bırakmakta bu nedenle hastalar 8 saatten fazla aç kalabilmektedir. Ayrıca araştırmamızda sağlık çalışanlarının ameliyat öncesi glikoz destekli sıvıları hastalara vermediklerini, bu tür uygulamalarının olmadığını ifade etmişlerdir. Bu nedenle hastaların metabolik olarak asidoza girip girmedikleri, kan şekerlerinin sonuçlarının ne olduğunu özellikle izlemedikleri belirlendi. Hastalara ameliyat sonrası sıvı desteğini tüm sağlık çalışanları vermekteydi, sadece ameliyat öncesi diyabet hastalarının kan şekeri takibi rutinde yapılmakta, hastaların açlık düzeylerinin kan şekerine, kan gazlarına (asidoz olarak) etkisi \%100 sağlık personeli tarafından izlenmemekteydi.

TUR-P ameliyatı olan hastaların genel anestezi yerine spinal anestezi ile ameliyat olması nedeniyle hastalarda kan şekerleri olumsuz etkilenmemiştir ifadesini \% $88 \quad(n=92.6)$ sağlık çalışanları kullandı. Bu bilgilere göre Gaziantep ili içinde yer alan üniversite ve devlet hastanelerinde TUR-P ameliyatlarında hastaların açlık süreleri klasik geleneksel uygulamalarla tedavi ve bakım aldığı, ASHİ protokolü ile uygulamalarının olmadığı belirlenmiştir.

ASHİ protokolüne göre hastalar genel anestezi sonrası en erken dönemde oral alıma başlaması, peristaltizmi hızlandırdığına hastanın iyileşme sürecini arttırdığına ve hastanedekalma süresiniazaltmaktadır(7). ASHİ protokollerine göre genel anestezi sonrası bilinci gelmiş hastaların en erken dönemde oral sıvı alabileceği ifade edilirken; araştırmamızda spinal anestezi ile TUR-P ameliyatı olan hastaların oral alım süresini sağlık çalışanlarından ameliyat sonrası \% $62.1(\mathrm{n}=59)$ ameliyat günü sıvı alımı, \% $3.2(\mathrm{n}=3)$ ameliyattan 4 saat sonra katı besin alımı olduğu öğrenildi.

TUR-P Ameliyatlarında ERAS-ASHI Protokolü ile Ameliyat Öncesi ve Sonrası Yapılması Gereken Ağrı Uygulamalarının Karşılaştırılması:

ASHİ protokolü kolon ve rektum ameliyatlarından sonra hastalarda bağırsak aktivitesini ve peristaltizmi en erken dönemde sağlamayı hedeflediği için epidural uygulamaların anestezi ve narkotik analjezik olarak bu ameliyatlarda önermese de; TUR-P ameliyatlarında epidural olarak opioidlerin tercih 
Tablo 3. TUR-P ameliyatlarında perioperatif hazırlı̆̆a yönelik uygulamaların incelenmesi

\begin{tabular}{|c|c|c|}
\hline Sorular & Say1 & $\%$ \\
\hline \multicolumn{3}{|c|}{ TUR-P ameliyatlarında, ameliyat öncesi hastalarınızın spinal anestezi açlık süresine yönelik uygulamalarınız nedir? } \\
\hline Hastaların ameliyattan önceki gece yarısından sonra aç bırakılması & 55 & 57.9 \\
\hline $\begin{array}{l}\text { Hastaların ameliyattan 4-6 saat önce katı gıdaların ve } 2 \text { saat öncesine sıvı gıdaların } \\
\text { kesilmesi }\end{array}$ & 4 & 4.2 \\
\hline Ameliyattan 8 saat önce katı ve sıvı gıdaların kesilmesi & 36 & 37.9 \\
\hline \multicolumn{3}{|c|}{ Sizce hastalarınıza TUR-P ameliyatı öncesi oral sıvı olarak karbonhidrattan zengin yükleme yapılmalı mı? } \\
\hline Evet & 28 & 29.5 \\
\hline Hayır & 67 & 70.5 \\
\hline \multicolumn{3}{|l|}{ Hastalarınız TUR-P ameliyatı sonrası ne zaman oral sıvı alıor? } \\
\hline Ameliyat günü & 59 & 62.1 \\
\hline Doktor isteyince & 10 & 10.5 \\
\hline Gaz çıkışı olunca & 26 & 27.3 \\
\hline \multicolumn{3}{|l|}{ Hastalarınız TUR-P ameliyatı sonrası ne zaman katı gıda alıyor? } \\
\hline Ameliyattan 4 saat sonra & 3 & 3.2 \\
\hline Ameliyattan 8 saat sonra & 25 & 26.5 \\
\hline Gaz çıkışı olunca & 67 & 70.5 \\
\hline \multicolumn{3}{|c|}{ TUR-P ameliyatı sonrası hastalarınıza bulantı kusma için profilaksi uyguluyor musunuz? } \\
\hline Evet & 62 & 65.3 \\
\hline Hayır (Dr orderında ihtiyaç halinde) & 33 & 34.7 \\
\hline \multicolumn{3}{|l|}{ Hastalarınızı ayağa kaldırıp yürüttüğünüz saat dilimi nedir? } \\
\hline İlk 52-56 saat sonra & 71 & 74.4 \\
\hline İlk 8-24 saatten sonra & 19 & 20.0 \\
\hline 24 saat sonra & 5 & 5.3 \\
\hline \multicolumn{3}{|c|}{$\begin{array}{l}\text { Spinal anestezi tercih edilen TUR-P ameliyatlarında, ameliyat sonrası dönemde kan şekerlerinde olumsuz etkiler oluyo } \\
\text { mu? }\end{array}$} \\
\hline Evet & 7 & 7.3 \\
\hline Hayır & 88 & 92.6 \\
\hline \multicolumn{3}{|l|}{ TUR-P ameliyatı geçirecek her hastaya antiembolik çorap uyguluyor musunuz? } \\
\hline Evet & 59 & 62.1 \\
\hline Hayır & 36 & 37.9 \\
\hline \multicolumn{3}{|l|}{ Hastalarınıza analjezik yapılmalı diyorsanız hangi ilaç kullanılmalıdır? } \\
\hline Antienflamatuar (intravenöz) & 42 & 44.2 \\
\hline Parasetemoller (intravenöz) & 32 & 33.7 \\
\hline Opioidepidural & 4 & 4.2 \\
\hline Opioid (intramüsküler) & 17 & 17.9 \\
\hline \multicolumn{3}{|c|}{ TUR-P ameliyatı olmuş tüm hastalarda taburcu olurken üriner kataterini çıkarıyor musunuz? } \\
\hline Evet & 60 & 63.1 \\
\hline Hayır & 35 & 36.8 \\
\hline
\end{tabular}

edilmesi hastaların ameliyat sonrası üçüncü güne kadar konforunu artırabilmektedir (11). Mitropoulos ve ark. 2002'de TUR-P ameliyatlarında hastaların ağrılarının sadece cerrahi travma değil, genital bölgede yapılan bir işlem olması, cinsel aktivitesini kaybedeceği korkusu, kanser gibi tanı konulacağı endişesi nedeniyle ağrıyı daha da artırabileceğini iletmiştir (13). Ameliyattan bir gün önce verilen hasta eğitimi anksiyeteyi ve ağrıyı azaltabilir. ASHİ protokolünde hastaların kaygılarını azaltmak için tasarlanmış işitsel görsel dokunsal eğitimlerin hemşire desteğiyle verilebileceği bildirilmektedir (14).

$\mathrm{Bu}$ nedenle araştırmamızda sağlık personellerinin hastalara verdikleri bilgilendirme sorulduğunda hastalara tasarlanmış işitsel görsel ve dokunma ile öğrenmeleri sağlayacakları eğitimlerin olmadığı tespit edildi. Hastalara yüz yüze ve rast gele tasarlanmamış plansız eğitim verme oranı \% $98.9(n=94)$ dur.

Hastaların kaygı düzeyleri ile ağrı düzeyleri olumsuz etkileneceği gerçeği ile araştırmamızda hastaların ağrılarının nasıl kontrol edildiği sorgulandığında epidural olarak narkotik analjezik uygulama oranının antiinflamatuar kullanımı \% 44.2 $(n=42)$, parasetamol kullanımı \% $33.7(n=32)$ olduğu saptandı. 
ASHI protokolüne göre diren, idrar kateteri gibi kateterlerin çıkartılması gerekmektedir bazı TUR-P ameliyatı sonrası hastaların kanama takibi idrar takibi sebebiyle idrar kateteri takılmakta, en erken ameliyat sonrası 1. gün çıkarılmaktadır (15). Araştırmamızda da üriner kateterlerin hasta taburcu olmadan çıkarılmadığı hatta bazı hastaların evlerine bile üriner kateter ile yollandığı belirlendi. Bu durumda hastalarda ağrının artışına neden olabilir.

TUR- P Ameliyatlarında ERAS-ASHI Protokolü ile Ameliyat Öncesi ve Sonrası Yapılması Gereken Erken Mobilizasyon Uygulamalarının Karşılaştırılması:

Anestezi almış tüm hastalarda ameliyat sonrası görülen en önemli komplikasyonlardan biri de derin ven trombozudur. Hastaların ameliyat sonrası en erken dönemde yataktan kalkması, oturması ve yürümesi DVT riskini azaltmaktadır. DVT riskini azaltan en önemli iki uygulamadan ilki düşük moleküllü antikoagülan uygulaması, diğeri de basınçlı çorap giydirerek venöz dönüşü sağlanmasıdır (16).

ASHİ Protokolüne göre; transüretral veya diğer düşük riskli ameliyatı olan hastalarda erken mobilizasyon dışında rutin tromboprofilaksi uygulamasına gerek yoktur. Araştırmamızda hastaların yürütülme düzeylerine bakıldığında 52-56 saat arasında yürütülme oranının $\% 74.4(\mathrm{n}=71)$ olduğu, antiembolik çorapların kullanımın da \% $37.9(\mathrm{n}=36)$ olduğu saptandı. Geerts ve ark.nin çalışmasına tam olarak uyulmadığı görüldü (16).

\section{Sonuç ve Öneriler}

Araştırmadan elde ettiğimiz bulgulara göre; Gaziantep ilinde yer alan hastanelerde ASHI uygulamalarına göre hastaların ameliyat öncesi aç kalmadı̆̆ı, oral karbonhitratlı sıvıları alıp almadığının belirlenmediği, hastalara planlı tasarlanmış ameliyat öncesi eğitimlerin verilmediği, hastaların ameliyattan sonra en erken dönemde oral sıvı almadığı, en erken dönemde yürütülmediği, hastaların ağrılarını azaltmak için sadece ilaç tedavisi uygulandığı belirlendi. Sonuç olarak tüm bulgulara göre ASHi protokolüne uygun bir bakım ve tedavi prosedürlerinin TUR-P ameliyatlarından sonra uygulanmadığı söylenebilir.

TUR-P ameliyatları sonrası geleneksel uygulamalar yerine ASHI protololü gibi kanıt temelli tedavi ve bakıma dayandırılmış hemşirelik bakım paketleri ve tedavi prosedürlerinin üroloji kliniklerinde uygulamaya başlatılması, bu nedenle tüm sağlı personellerine ASHİ uygulamaları konusunda bilgilerin verilmesi, hizmet içi eğitimlerin planlanması, tüm personelin ASHİ protokolüne benzeyen prosedürler oluşturması ve araştırmalar yapması için komitelerin kurulması sağlanabilir.

\section{KAYNAKLAR}

1. Stevens KR. The impact of evidence-based practice in nursing and the next big ideas. Online J Issues Nurs. 2013; 18: 4 .

2. Ersoy E, Gündoğdu H. Preoperatif aralıkta değişen kavramlar. Ulusal Cerrahi Dergisi 2005; 21: 96-101.

3. Basse L, HjortJakobsen D, Billesbolle P, Werner M, Kehlet $\mathrm{H}$. A clinical path way to accelerate recovery after colonic resection. Annals of Surgery 2000; 232: 51-7.
4. Kehlet H, Wilmore DW. Evidence based surgical care and the evolution of fast track surgery. Annals of Surgery 2008; 248: 189-198.

5. Harris S R, Hugi M R, Olivatto A, Levine M. Clinical pratice guidelines fort he care and treatment of brest cancer: Lymphedema Canadian Edical Association Journal. 2001; 164:, 191-9.

6. Tuna PT, Kurşun Ş. Kolerektal cerrahide hızlandırılmış bakım protokolleri ve hemşirelik bakımı. Dokuz Eylül Üniversitesi Hemşirelik Fakültesi Elektronik Dergisi 2018; 11:180-8.

7. Ersoy E, Gündoğdu H. Cerrahi sonrası iyileşmenin hızlandirılması. Ulusal Cerrahi Dergisi 2007; 23: 35-40.

8. Kehlet H, Wilmore DW. Multimodal strategies to improve surgical out come. The American Journal of Surgery 2002; 183: 630- 41.

9. Kehlet H, Wilmore DW. Fast-tracksurgery. British Journal of Surgery 2005; 92: 3-4.

10. Cerantola $Y$, Valerio M, Persson B, Jichlinski P, Ljungqvist $\mathrm{O}$, Hubner M, et al. Guidelines for perioperative care after radical cystectomy for bladder cancer: Enhanced Recovery After Surgery (ERAS $\left(^{\circ}\right)$ ) society recommendations. Clinical Nutrition, 2013, 32: 879-87.

11. Yuill KA, Richardson RA, Davidson RA, Garden OJ, Parks RW. The administration of anoral carbohydrate containing fluid priorto majör elective upper-gastrointestinal surgery preserves skeletal musclemass postoperative randomised clinical trial. Clinical Nutrition 2005; 24: 32-7.

12. Block BM, Liu SS, Rowlingson AJ, Cowan AR, Cowan JA, $\mathrm{Wu}$ CL. JAMA. Efficacy of postoperative epidural analgesia: a meta-analysis.2003; 290: 2455-63.

13. Mitropoulos D, Anastasiou I, Giannopoulou C, Nikolopoulos P, Alamanis C, Zervas A, et al. Symptomatic benign prostate hyperplasia: Impact on partners' quality of life. European Urology 2002; 41: 240-4.

14. Gustafsson UO, Scott MJ, Schwenk W, Demartines N, Roulin D, Francis N, et al. Guidelines for perioperative care in elective colonic surgery: enhanced recovery after surgery (ERAS) society recommendations. World Journal of Surgery 2013; 37: 259-84.

15. Nygren J, Thacker J, Carli F, Fearon KC, Norderval S, Lobo $\mathrm{DN}$, et al. Guidelines for perioperative care in elective rectal/pelvic surgery: Enhanced recovery afters surgery society recommendations. World Journal of Surgery 2013; 37: 285-305.

16. Geerts WH, Bergqvist D, Pineo GF, Heit JA, Samama CM, Lassen MR, et al. American college of chest physicians evidence-based clinical practice guidelines prevention of venous thromboembolism. Chest 2008; 133(6 suppl.): 381-453. 